\title{
Effect of glycine as an impurity on the properties of Epsomite single crystals
}

\author{
J.M.Kavitha and C.K.Mahadevan \\ Physics Research Centre, S.T.Hindu College, \\ Nagercoil-629 002, Tamilnadu, India
}

\begin{abstract}
Epsomite $\left(\mathrm{MgSO}_{4} .7 \mathrm{H}_{2} \mathrm{O}\right)$ is a hydrogen bonded crystal having a wide range of applications in various fields. Pure and glycine added Epsomite (a total of six) single crystals have been grown and characterized in order to investigate the effect of glycine as an impurity on the properties of Epsomite crystals.The densities and lattice parameters observed indicate that the impurity molecules have entered into the crystal matrix. The grown crystals exhibit good optical transparency in the wavelength range 210-1100 nm. Second harmonic generation measurements indicate that they are nonlinear optically active. Results obtained through microhardness measurements follow the normal indentation size effect. Electrical (AC and DC) measurements indicate that all the six crystals grown in the present study exhibit a normal dielectric behavior and the electrical conduction is understood to be due to the protonic movement. Moreover, glycine addition is found to reduce $\varepsilon_{r}$ value significantly indicating the possibility of Epsomite crystal becoming a low $-\varepsilon_{r}$ value dielectric material.
\end{abstract}

Keywords: Crystal growth, Epsomite crystals, Electrical properties, Mechanical properties, Optical properties, Single crystals, $X$-ray diffraction

\section{Introduction}

Epsomite (magnesium sulfate heptahydrate, $\mathrm{MgSO}_{4} \cdot 7 \mathrm{H}_{2} \mathrm{O}$ ) is a widespread evaporate mineral and has played a number of roles of scientific interest over the last four centuries [1]. It is a hydrogen bonded single crystal and is isomorphous with Morenosite (nickel sulfate heptahydrate, $\mathrm{NiSO}_{4} \cdot 7 \mathrm{H}_{2} \mathrm{O}$ ) and Goslarite (zinc sulfate heptahydrate, $\mathrm{ZnSO}_{4} \cdot 7 \mathrm{H}_{2} \mathrm{O}$ ). It has numerous medical and pharmaceutical applications, for example, in the treatment of cardiac arrhythmia, acute asthma, eclampsia and gallstones. It is used in agriculture (fertilizer), cotton and silk manufacturing, ore processing and as an additive in explosives. It is a raw material for manufacturing various chemicals containing magnesium and also has applications in the field of dosimetric measurements and luminescence studies [2,3].

Epsomite crystallizes in the orthorhombic crystal system with tetramolecular unit cells having the space group $\mathrm{P} 22_{1} 2_{1} 2_{1}$. The structure consists of an octahedron formed by $\mathrm{Mg}^{2+}$ bonded to six water $\left(\mathrm{H}_{2} \mathrm{O}\right)$ molecules and a tetrahedron formed by $\mathrm{S}^{6+}$ ion bonded to four $\mathrm{O}^{2-}$ ions. One additional water molecule participates in linking these structural elements with a network of weak hydrogen bonds. At near ambient temperature, this interstitial seventh water molecule is easily lost to leave the material hexahydrated. Epsomite crystal is colorless and the unit cell parameters [4] are: $a=11.86, b=11.99$ and $c=6.858 \AA$. It is highly soluble in water and the solubility at room temperature (at $33{ }^{\circ} \mathrm{C}$ ) is $115 / 100 \mathrm{ml}$ of water. The molecular weight, mean refractive index and density are $246.48,1.485$ and $1.68 \mathrm{~g} / \mathrm{cc}$ respectively [5].

Pure Epsomite crystals have been grown at low temperature from aqueous solutions [6-12]. The presence of foreign particles in the growth medium has long been recognized in changing the growth habits of crystals[13,14]. Jibbouri et al [14] found that the impurities ( $\mathrm{KCl}, \mathrm{K}_{2} \mathrm{SO}_{4}, \mathrm{NaCl}$ and $\mathrm{MgCl}_{2}$ ) exert influence on the saturation and supersaturation limit. Ferdous and Podder [12] found that the optical quality of the Epsomite crystal improves on doping with $\mathrm{KCl}$. Also, their dielectric studies showed that $\mathrm{KCl}$ doped Epsomite possesses low dielectric constant and low dielectric loss which could be suitable for electro-optic applications. Mahadevan[10] has observed larger electrical conductivities for the impurity $\left(\mathrm{KCl}\right.$ and $\left.\mathrm{KNO}_{3}\right)$ added Epsomite single crystals. Mahadevan and his co-workers have reported on Epsomite forming mixed crystals with Goslarite and Morenosite along with some other studies [15-17]. As Epsomite is cheap, non-toxic and noncorrosive, it was studied by Van Essen and his co-workers [18 ] as a possible thermochemical material (TCM) for solar seasonal heat storage.

The $\mathrm{SO}_{4}$ group in $\mathrm{MgSO}_{4} .7 \mathrm{H}_{2} \mathrm{O}$ may be considered similar to the $\mathrm{PO}_{4}$ group (having tetrahedral geometry) in $\mathrm{NH}_{4} \mathrm{H}_{2} \mathrm{PO}_{4}(\mathrm{ADP})$ and $\mathrm{KH}_{2} \mathrm{PO}_{4}(\mathrm{KDP})$. Mahadevan and his co-workers $[19,20]$ have reported the possibility of reducing the $\varepsilon_{\mathrm{r}}$ (dielectric constant) value by adding simple organic compounds such as urea and L-arginine to KDP. Several researchers have studied the effect of impurities (both organic and inorganic) on the nucleation, growth and physical properties of some hydrogen-bonded crystals like KDP and ADP. However, only limited studies have been done on Epsomite crystals. 
In the present study, aiming at discovering new useful materials, we have grown Epsomite (MSH) single crystals by the free evaporation method and investigated the effect of glycine (a simple and interesting amino acid) as an impurity (added in the Epsomite solution used for the growth of single crystals) with impurity concentration ranging from 2000- 10000 ppm (i.e. 0.2 - 1.0 mol\%) on the properties of Epsomite. Six crystals (in total) were grown and characterized structurally, chemically, optically, mechanically and electrically. Results obtained are herein reported and discussed.

\subsection{Crystal growth}

\section{II.Experimental Details}

Analytical Reagent (AR) grade samples (without further purification) of $\mathrm{MgSO}_{4} \cdot 7 \mathrm{H}_{2} \mathrm{O}$ and glycine along with double distilled water were used for the growth of single crystals. Aqueous solution of the required salt (pure or glycine doped) was prepared at a supersaturated concentration and allowed to equilibrate at the desired temperature in a nucleation cell (corning glass vessel). In the unstirred condition, small crystals appeared in the beginning due to slow evaporation and grew larger in considerable finite time. Defect-free and highly transparent crystals were selected from the above and used for the characterization measurements. In all the crystal growth experiments, the temperature and volume were kept constant respectively at $30^{\circ} \mathrm{C}$ and $25 \mathrm{ml}$. Concentration programming was done to get good single crystals by using various supersaturated concentrations between 2.8 and 3.5. Good Epsomite single crystals could be obtained from $3.15 \mathrm{M}$ solution. This concentration was considered for growing the glycine added Epsomite single crystals. Single crystals were grown from pure $\left(\mathrm{MgSO}_{4} .7 \mathrm{H}_{2} \mathrm{O}\right)$ and five impurity (glycine) added (with impurity concentrations, viz. 0.2, 0.4, 0.6, 0.8 and 1.0 mole \%) solutions.

\subsection{Characterization}

Flotation method $[21,22]$ was used to determine (within an accuracy of $\pm 0.008 \mathrm{~g} / \mathrm{cc}$ ) the density of the grown crystals. Bromoform of density $2.890 \mathrm{~g} / \mathrm{cc}$ and carbon tetrachloride of density $1.594 \mathrm{~g} / \mathrm{cc}$ are respectively the denser and rarer liquids used. Fourier transform infrared (FTIR) spectra were recorded for all the six crystals grown by the $\mathrm{KBr}$ pellet method in the wave number range $400-4000 \mathrm{~cm}^{-1}$ by employing a SHIMADZU spectrometer. X-ray powder diffraction (PXRD) data were recorded in the $2 \theta$ range $10-70{ }^{\circ}$ using an automated X-ray powder diffractometer (PANalytical) with monochromated $\mathrm{Cu} \mathrm{K \alpha}$ radiation $(\lambda=1.54056 \AA)$. The reflections were indexed following the procedures of Lipson and Steeple [23]. Lattice parameters were also determined.

The UV-Vis-NIR transmittance spectra were recorded for all the six grown crystals (dissolved in water) in the wavelength range 190-1100 nm by using a Lambda-35 spectrophotometer. The second harmonic generation (SHG) test was carried out by theKurtz and Perry method [24] using a Nd-YAG Quanta ray laser (with fundamental radiation of wavelength $1064 \mathrm{~nm}$ ).Vicker's hardness measurements were carried out using a SHIMADZU HMV2 microhardness tester.

DC electrical conductivity measurements were carried out to an accuracy of $\pm 2.5 \%$ crystals along the cdirection (major growth direction) by the conventional two-probe technique using a million megohm meter at various temperatures ranging from $35-65{ }^{\circ} \mathrm{C}$ in a way similar to that followed by Mahadevan and his co-workers $[21,22,25]$. The above temperature range was considered due to the thermal instability of these crystals beyond about $70{ }^{\circ} \mathrm{C}$. Beyond this temperature, the crystals were found to loose slowly the transparency indicating the slow release of water molecules with increasing temperature. Temperature of the experiment was controlled to an accuracy of $\pm 1{ }^{\circ} \mathrm{C}$. Single crystals with high transparency and large surface defect-free (i.e. without any scratch or crack or pit on the surface, tested with a traveling microscope) size (>3 mm) were selected for the electrical measurements. The extended portions of the crystals were removed completely and the opposite faces were polished and coated with good quality graphite to obtain a good conductive surface layer. The dimensions of the crystals were measured using a traveling microscope (Least count $=0.001 \mathrm{~cm})$. The DC conductivity $\left(\sigma_{\mathrm{dc}}\right)$ of the crystal was calculated using the relation:

$$
\sigma_{\mathrm{dc}}=\mathrm{d}_{\text {crys }} /\left(\mathrm{R}_{\text {crys }}\right)
$$

where $\mathrm{R}$ is the measured resistance, $\mathrm{d}_{\text {crys }}$ is the thickness of the sample crystal and $\mathrm{A}_{\text {crys }}$ is the area of the face of the crystal in contact with the electrode.

The capacitance $\left(\mathrm{C}_{\text {crys }}\right)$ and dielectric loss factor $(\tan \delta)$ measurements were carried out to an accuracy of $\pm 2 \%$ by the parallel plate capacitor method using an LCR meter (Systronics make) with a fixed frequency of $1 \mathrm{kHz}$ at various temperatures ranging from $35-65{ }^{\circ} \mathrm{C}$ along the c-direction in a way similar to that followed by Mahadevan and his co-workers [25-27]. The required sample crystals were prepared as in the case of DC conductivity measurements. Here also, the observations were made while cooling the sample crystal and the experimental temperature was controlled to an accuracy of $\pm 1^{\circ} \mathrm{C}$. Air capacitance $\left(\mathrm{C}_{\text {air }}\right)$ was measured only at 
the lower temperature considered, as the temperature variation of air capacitance was found to be negligible. As $\mathrm{A}_{\text {crys }}$ was smaller than the plate area of the cell, the dielectric constant of the crystal $\left(\varepsilon_{\mathrm{r}}\right)$ was calculated using Mahadevan's formula [25,28,29]:

$\varepsilon_{\mathrm{r}}=\left[\mathrm{A}_{\text {air }} / \mathrm{A}_{\text {crys }}\right]\left[\left[\mathrm{C}_{\text {crys }}-\mathrm{C}_{\text {air }}\left[1-\mathrm{A}_{\text {crys }} / \mathrm{A}_{\text {air }}\right]\right] / \mathrm{C}_{\text {air }}\right]$

where $\mathrm{C}_{\text {crys }}$ is the capacitance with crystal (including air), $\mathrm{C}_{\text {air }}$ is the capacitance of air and $\mathrm{A}_{\text {air }}$ is the area of the electrode. The AC electrical conductivity $\left(\sigma_{\mathrm{ac}}\right)$ was calculated using the relation:

$$
\sigma_{\mathrm{ac}}=\varepsilon_{0} \varepsilon_{\mathrm{r}} \omega \tan \delta
$$

where $\varepsilon_{0}$ is the permittivity of free space and $\omega$ is the angular frequency of the applied field.

\subsection{Densities and lattice parameters}

\section{III.Results And Discussion}

A photograph of the sample crystals grown is shown in Figure 1. Crystals up to a size of about $2 \mathrm{~cm}$ were obtained. All the six crystals grown are found to be stable in normal atmosphere. It was observed that the difference in densities of crystals grown in the same growth cell was very small and negligible. Average densities are given in Table 1. The density value obtained in the present study for pure Epsomite compares well with that reported in the literature. For the glycine added systems, the density decreases when the impurity concentration increases. The density variation shows clearly that the glycine molecules have entered nearly proportionately into the Epsomite crystal matrix as per the glycine concentration considered for the aqueous solution used for the growth of single crystals.

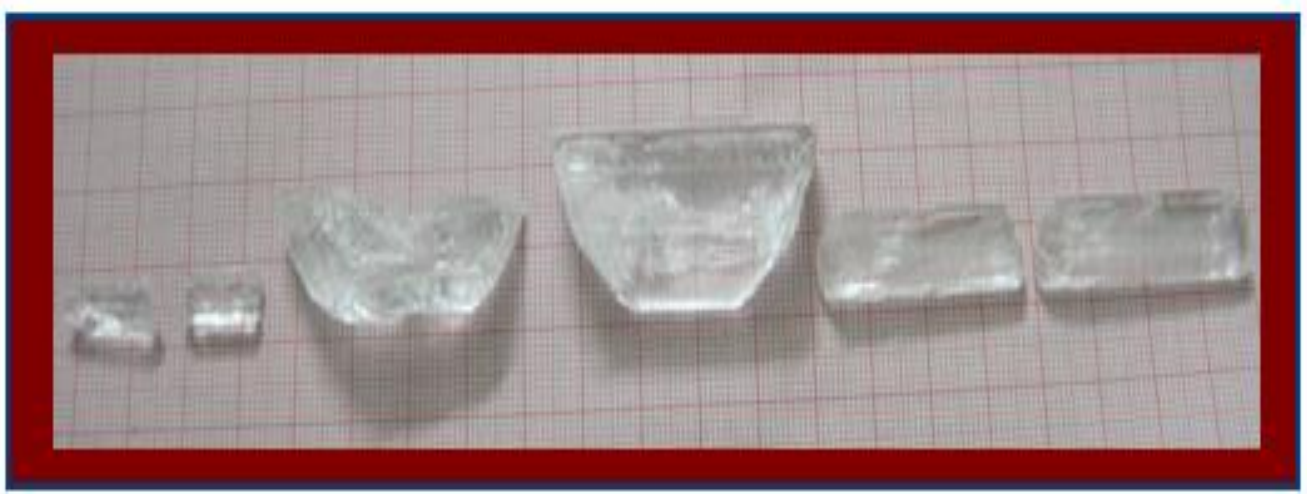

Figure 1:Photograph showing the pure and glycine doped Epsomite single crystals grown [From left-Pure Epsomite and 0.2, 0.4, 0.6, 0.8 and 1.0 mole\% glycine doped Epsomite]

Table 1: Average densities and lattice parameters observed for the pure and glycine doped Epsomite crystals.

\begin{tabular}{|c|c|c|c|c|c|}
\hline \multirow{2}{*}{$\begin{array}{c}\text { System ( with impurity } \\
\text { concentration in the solution, } \\
\text { mole } \% \text { ) }\end{array}$} & \multirow{2}{*}{$\begin{array}{c}\text { Density } \\
\text { (g/cc) }\end{array}$} & \multicolumn{4}{|c|}{ Lattice parameters } \\
\hline & & $\mathbf{a}(\AA)$ & $\mathbf{b}(\AA)$ & $\mathbf{c}(\AA)$ & Volume $\left(\AA^{3}\right)$ \\
\hline Pure Epsomite & 1.668 & 12.001 & 12.509 & 6.623 & 994.2 \\
\hline \multicolumn{6}{|l|}{ Glycine addedEpsomite } \\
\hline 0.2 & 1.664 & 11.753 & 12.207 & 6.857 & 983.8 \\
\hline 0.4 & 1.661 & 11.816 & 12.263 & 6.773 & 981.4 \\
\hline 0.6 & 1.658 & 11.931 & 12.439 & 6.586 & 977.4 \\
\hline 0.8 & 1.655 & 11.913 & 12.226 & 6.623 & 964.6 \\
\hline 1.0 & 1.651 & 11.925 & 12.247 & 6.586 & 961.9 \\
\hline
\end{tabular}

The PXRD patterns recorded for the grown crystals are shown in Figure 2. Appearance of strong and sharp peaks confirms the crystalline nature of the grown crystals. The diffraction peaks were indexed for the orthorhombic system. The estimated lattice parameters are given in Table 1. The lattice parameters obtained for the pure Epsomite compare well with that reported in the literature. The change in the lattice volume observed due to glycine addition indicates that the glycine molecules have entered into the Epsomite crystal matrix. Also, it is observed that glycine addition does not distort the crystal structure significantly. 


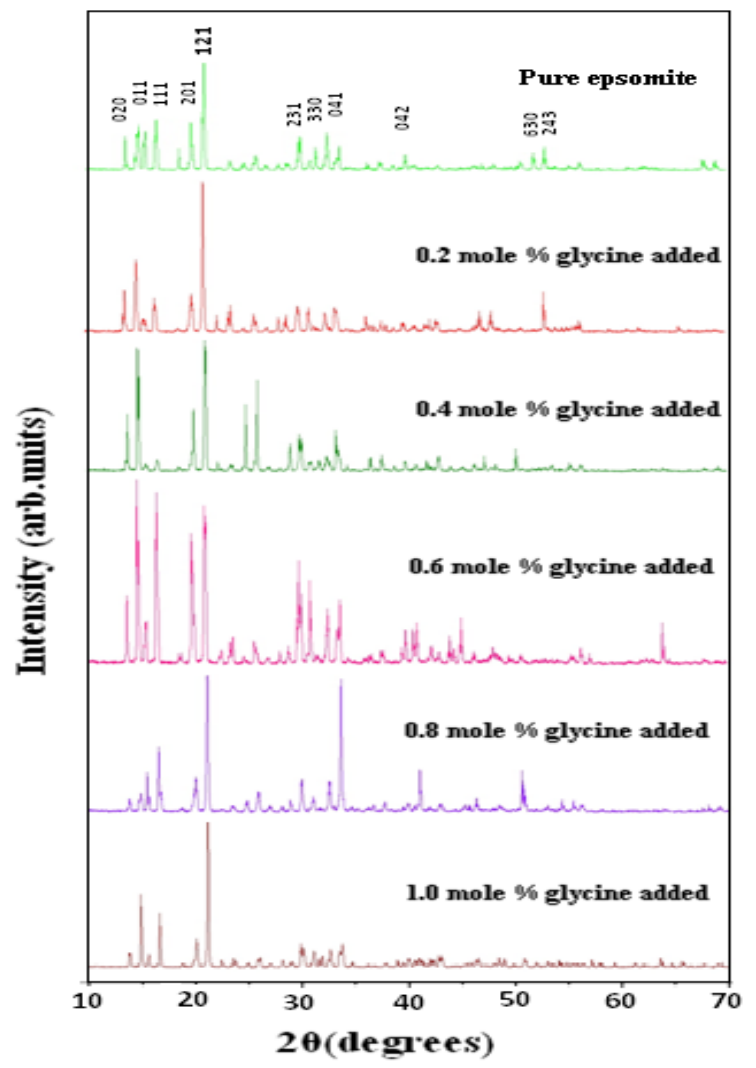

Figure 2: The PXRD patterns observed for the pure and glycine doped Epsomite crystals

\subsection{FTIR spectra}

The observed FTIR spectra are shown in Figure 3. Table 2 contains the band assignments. Significant difference could not be observed for the doped crystals. The $\mathrm{SO}_{4}{ }^{2-}$ ion presents four normal modes in the infrared region : a non-degenerate symmetric bending $v_{1}$, a doubly degenerate symmetric bending $v_{2}$, and two triply degenerate symmetric stretching and bending $v_{3}$ and $v_{4}$ respectively [1]. Changes in protonation, salvation and metal complexation of $\mathrm{SO}_{4}{ }^{2-}$ can modify S-O bond length and, consequently, may change the symmetry of the anion (sulfate ion). The change in symmetry leads to a shift in the vibrational bands to different wave numbers and causes the degenerate vibrations to become non-degenerate.

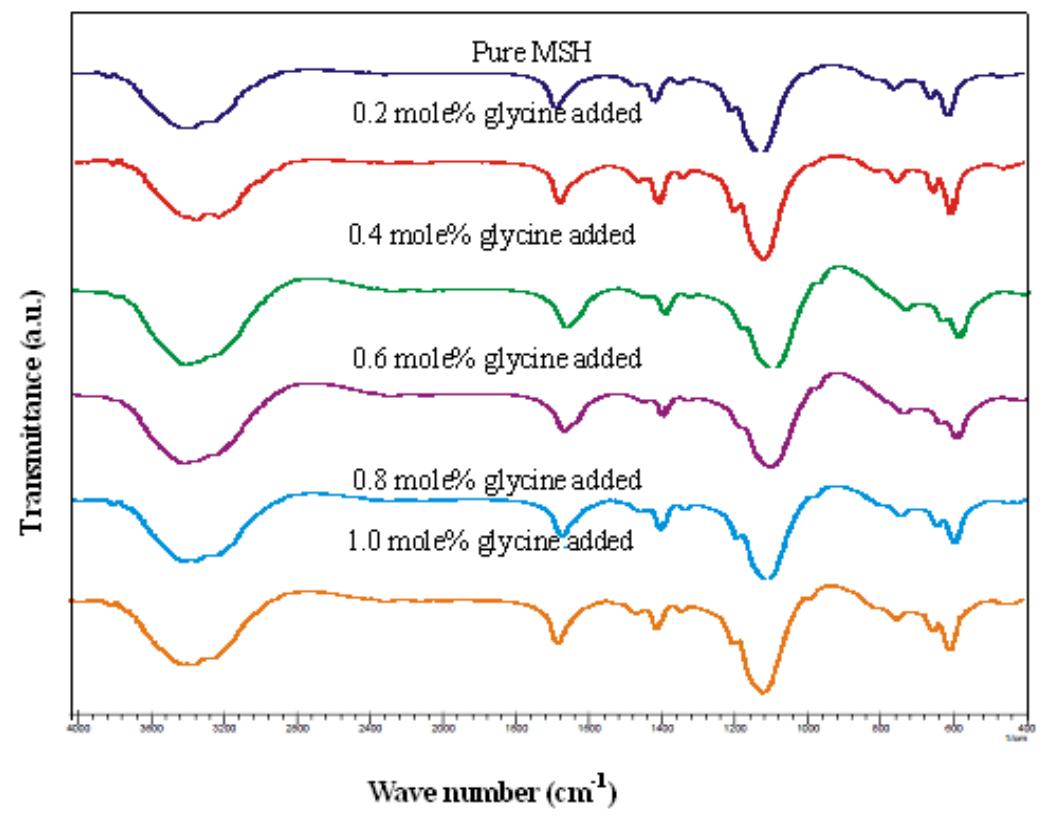

Figure 3: FTIR spectra observed for the pure and glycine doped $\mathrm{MgSO}_{4} \cdot 7 \mathrm{H}_{2} \mathrm{O}$ crystals 
Table 2: The FTIR spectral (vibrational) band assignments for the pure and glycine doped Epsomite crystals

\begin{tabular}{|c|c|c|c|c|c|c|}
\hline \multicolumn{6}{|c|}{ Wave numbers $\left(\mathrm{cm}^{-1}\right)$ observed for } & \multirow{2}{*}{ Band assignment } \\
\hline Epsomite & $\begin{array}{l}0.2 \text { mole } \% \\
\text { glycine } \\
\text { added }\end{array}$ & $\begin{array}{l}0.4 \text { mole \% } \\
\text { glycine } \\
\text { added }\end{array}$ & $\begin{array}{c}0.6 \text { mole \% } \\
\text { glycine added }\end{array}$ & $\begin{array}{c}0.8 \text { mole \% } \\
\text { glycine added }\end{array}$ & $\begin{array}{c}1.0 \text { mole \% } \\
\text { glycine added }\end{array}$ & \\
\hline 3377 & 3371 & \multirow[t]{3}{*}{3394} & 3394 & 3383 & 3377 & \multirow{3}{*}{$\begin{array}{l}\text { Presence of } \mathrm{H}_{2} \mathrm{O} \\
\text { molecules (free water } \\
\text { symmetric stretch) }\end{array}$} \\
\hline 3319 & 3315 & & & 3321 & 3319 & \\
\hline 3211 & 3200 & & & 3211 & 3209 & \\
\hline 1670 & 1670 & 1668 & 1668 & 1670 & 1670 & $\begin{array}{l}\mathrm{OH}_{2} \text { bending mode } \\
\text { (asymmetric stretch) }\end{array}$ \\
\hline 1454 & 1454 & 1452 & 1454 & 1452 & 1454 & \multirow[t]{2}{*}{ Combination bond } \\
\hline 1398 & 1400 & 1400 & 1400 & 1400 & 1400 & \\
\hline 1194 & 1194 & 1192 & 1192 & 1194 & 1194 & \multirow[t]{2}{*}{$\begin{array}{l}v_{3} \mathrm{SO}_{4} \text { (asymmetric } \\
\text { stretch) }\end{array}$} \\
\hline 1113 & 1113 & 1111 & 1111 & 1113 & 1113 & \\
\hline 752 & 752 & 750 & 750 & 750 & 750 & $\begin{array}{l}v_{4} \mathrm{SO}_{4} \text { (bending } \\
\text { mode) }\end{array}$ \\
\hline 652 & 652 & 650 & 650 & 652 & 6527 & \multirow{2}{*}{$\begin{array}{l}\mathrm{v}_{4} \mathrm{SO}_{4} \text { (stretching } \\
\text { vibration) }\end{array}$} \\
\hline 606 & 606 & 606 & 606 & 606 & 606 & \\
\hline 460 & 445 & 450 & 445 & 450 & $450]$ & \multirow[t]{2}{*}{$\begin{array}{l}\mathrm{H}_{2} \mathrm{O} \text { (bending mode, } \\
\text { asymmetric stretch) }\end{array}$} \\
\hline 430 & 420 & 420 & 425 & 430 & 420 & \\
\hline
\end{tabular}

The symmetric $\mathrm{SO}_{4}{ }^{2-}$ stretch $v_{3}$ appears at $1194-1111 \mathrm{~cm}^{-1}$. The bending modes of $\mathrm{SO}_{4}{ }^{2-}\left(v_{4}\right)$ are positioned at around $752-750$ and $652-606 \mathrm{~cm}^{-1}$. The broad envelope around $3394-3200 \mathrm{~cm}^{-1}$ indicates the presence of water and it belongs to free water symmetric stretch. The asymmetric stretch of water has been observed at 1670-1668 $\mathrm{cm}^{-1}$. The water bending mode has been observed at around $450-420 \mathrm{~cm}^{-1}$. The observed spectra for all the crystals grown are similar to that reported in the literature for $\mathrm{MgSO}_{4} \cdot 7 \mathrm{H}_{2} \mathrm{O}[1,30,31]$.

\subsection{Optical properties}

The UV-Vis-NIR transmittance spectra observed for the pure and glycine added Epsomite crystals are shown in Figure 4. All the spectra are found to be similar and show wide transmission window with a small dip at around $390 \mathrm{~nm}$ in the UV-Vis-NIR region (from 210-1100nm). This enables these crystals to be potential candidates for opto-electronic applications. Efficient nonlinear optical (NLO) crystals have optical transparency lower cut-off wavelengths between 200 and $400 \mathrm{~nm}$ [32]. This indicates that all six crystals grown in the present study can be considered as promising NLO crystals. 


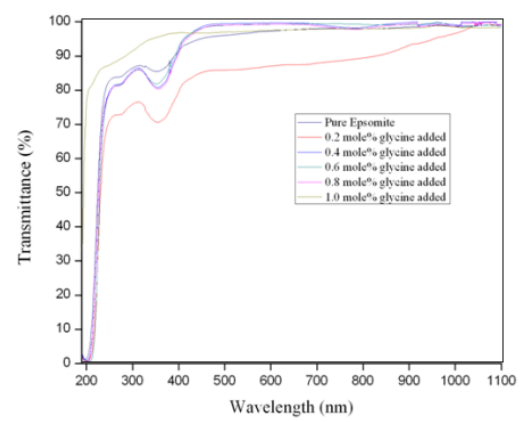

Figure 4: The UV-Vis-NIR spectra observed for the pure and glycine doped $\mathrm{MgSO}_{4} .7 \mathrm{H}_{2} \mathrm{O}$ crystals

Results obtained in the second harmonic generation (SHG) test conducted on all the grown crystalsindicate that all the six crystals grown are NLO active. The SHG efficiencies (compared to that of KDP) obtained are given in Table 3. The efficiency is maximum for pure Epsomite and minimum for 1.0 mole\% glycine added Epsomite crystal.

Table 3: The SHG efficiencies and work hardening coefficients observed for the pure and glycine doped Epsomite crystals

\begin{tabular}{ccc}
\hline $\begin{array}{c}\text { System (with impurity concentration } \\
\text { in the solution, mole \%) }\end{array}$ & $\begin{array}{c}\text { SHG efficiency (in } \\
\text { KDP unit) }\end{array}$ & $\begin{array}{c}\text { Work hardening } \\
\text { co-efficients (n) }\end{array}$ \\
\hline Pure Epsomite & 0.70 & 9.11 \\
0.2 & 0.66 & 5.76 \\
0.4 & 0.58 & 3.38 \\
0.6 & 0.60 & 3.12 \\
0.8 & 0.64 & 6.62 \\
1.0 & 0.55 & 4.77 \\
\hline
\end{tabular}

\subsection{Mechanical properties}

The hardness behavior and $\log \mathrm{P}$ versus log $\mathrm{d}$ plots for the pure and glycine added Epsomite crystals are shown in Figure 5. P is the load applied and d is the diagonal length of the indentation made on the crystal surface. The Vicker's hardness number is defined as

$$
\mathrm{H}_{\mathrm{v}}=1.8544 \mathrm{P} / \mathrm{d}^{2} \mathrm{~kg} / \mathrm{mm}^{2}
$$

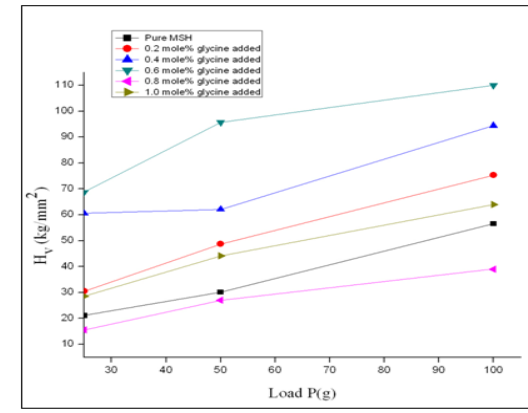

(a)

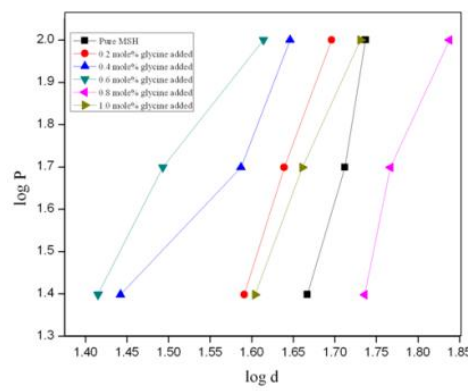

(b)

Figure 5: The hardness behavior (a) and $\log P$ versus $\log d$ plots(b) observed for the pure and glycine doped $\mathrm{MgSO}_{4} \cdot 7 \mathrm{H}_{2} \mathrm{O}$ crystals 
The hardness number increases with increasing load (see Fig.5(a)) for all the six crystals studied. It increases up to a load of $100 \mathrm{~g}$, above which cracks start developing. This may be due to the release of internal stress generation with indentation. The work hardening coefficients (n) estimated from the slopes of the bestfitted straight lines of $\log \mathrm{P}$ versus $\log \mathrm{d}$ curves (see Fig. 5(b)) are given in Table 3.

The Meyer's law [33] is expressed as

$$
\mathrm{P}=\mathrm{k}_{1} \mathrm{~d}^{\mathrm{n}}
$$

where $\mathrm{k}_{1}$ is the material constant. Combination of equations (4) and (5) leads to the relation

$\mathrm{H}_{\mathrm{v}}=\mathrm{b} \mathrm{P}^{(\mathrm{n}-2) / \mathrm{n}}$

where $\mathrm{b}=1.8544 \mathrm{k}_{1}{ }^{(1+2 / \mathrm{n})}$, a new constant. The above relation indicates that $\mathrm{H}_{\mathrm{v}}$ should increase with the load if $\mathrm{n}>2$. The experimental data observed in the present study is in good agreement with the above confirming the normal indentation size effect (ISE) [34]. Onitsch and Hanneman have found that ' $n$ ' should lie between 1.0 and 1.6 for hard materials and above 1.6 for soft ones [34]. The ' $n$ ' values observed in the present study are all more than 1.6 which indicates that all the six crystals grown belong to the soft materials category.

\subsection{Electrical properties}

The electrical parameters, viz., $\sigma_{\mathrm{dc}}, \varepsilon_{\mathrm{r}}, \tan \delta$ and $\sigma_{\mathrm{ac}}$ observed in the present study are shown in Figures 6-9. All the four electrical parameters are found to increase with the increase in temperature. This is a normal dielectric behavior. This can be understood on the basis that the mechanism of polarization is similar to the conduction process. The electronic exchange of the number of ions in the crystal gives local displacement of electrons in the direction of the applied field, which in turn gives rise to polarization.

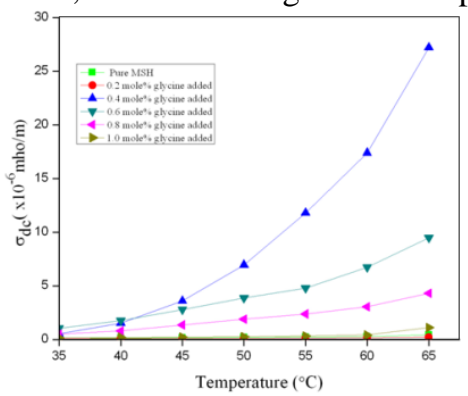

Figure 6: The DC electrical conductivities $\left(\sigma_{\mathrm{dc}}\right)$ observed for the pure and glycine doped $\mathrm{MgSO}_{4} \cdot 7 \mathrm{H}_{2}$ Ocrystals

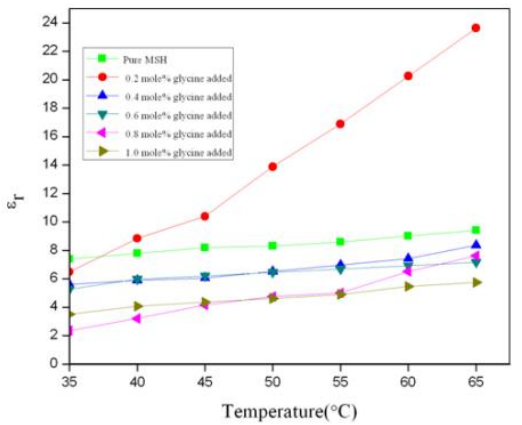

Figure 7:The dielectric constants $\left(\varepsilon_{\mathrm{r}}\right)$ observed for the pure and glycine doped $\mathrm{MgSO}_{4} .7 \mathrm{H}_{2} \mathrm{O}$ crystals

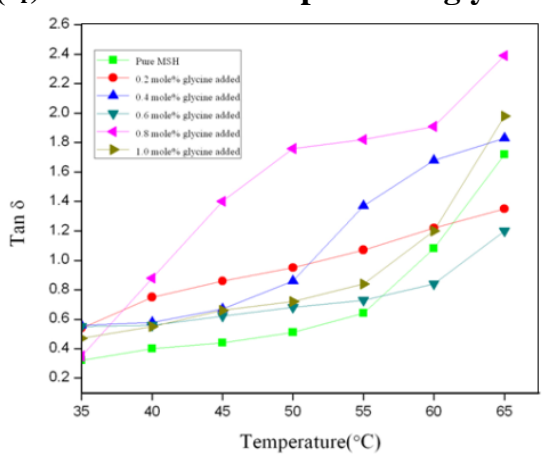

Figure 8: The dielectric loss factors $\left(\tan \delta\right.$ ) observed for the pure and glycine doped $\mathrm{MgSO}_{4} \cdot 7 \mathrm{H}_{2} \mathrm{O}$ crystals 


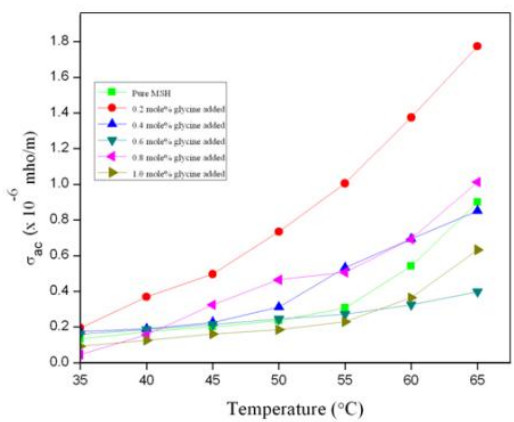

Figure 9 :The AC electrical conductivities ( $\left.\sigma_{a c}\right)$ observed for the pure and glycine doped $\mathrm{MgSO}_{4} \cdot 7 \mathrm{H}_{2} \mathrm{O}$ crystals

Electrical conduction in Epsomite crystals may be determined by the proton transport within the framework of hydrogen bonds. A combination of the following two mechanisms may be considered. The first mechanism is identical to the conductivity mechanism in ice also containing hydrogen bonds. According to the second mechanism, conductivity is associated with the incorporation into the crystal lattice of impurities and the formation of corresponding defects in ionic crystals. The proton conduction may be accounted for by motion of protons accompanied by a D defect (access of positive charge). Migration of these defects may only modify electric polarization and may not change the charge at an electrode [35]. The motion of defects occurs by some kind of rotation in the bond with defects. The speed of displacement $v=v a$, where a and $v$ are the distance and frequency respectively of the jump from one bond to the other. When the temperature of the crystal is increased there is a possibility of weakening of the hydrogen bonding system due to rotation of the hydroxyl ions in water molecules. The increase of conductivity with the increase in temperature observed in the present study can be understood as due to the temperature dependence of the proton transport.

Variation of $\varepsilon_{\mathrm{r}}$ with temperature is generally attributed to the crystal expansion, the electronic and ionic polarizations and the presence of impurities and crystal defects. The variation at low temperature is mainly due to the expansion and electronic and ionic polarizations. The increase at higher temperatures is mainly attributed to the thermally generated charge carriers and impurity dipoles. Varotsos [36] has shown that the electronic polarizability practically remains constant in the case of ioinic crystals. The increase in dielectric constant with temperature is essentially due to the temperature variation of ionic polarizability.

All the four electrical parameters considered in the present study do not vary systematically with the impurity concentration. It is a known fact that glycine is a simple organic molecule and is expected to occupy the interstitial positions. The density measurement and PXRD analysis show a small decrease of density and lattice volume with the increase of impurity concentration taken in the solution used for the growth of single crystals. Moreover, the impurity concentrations considered in the present study are small. So, the impurity molecules can be assumed to replace the water molecules and ions $\left(\mathrm{Mg}^{2+}\right.$ and $\left.\mathrm{SO}_{4}{ }^{2-}\right)$ to some extent in addition to occupying the interstitials in the Epsomite crystal matrix creating a disturbance in the hydrogen bonding system. As the conduction in Epsomite is protonic and mainly due to the water molecules and $\mathrm{SO}_{4}{ }^{2-}$ ions, the disturbance in the hydrogen bonding system may cause the conductivity to vary nonlinearly with the impurity concentration.

It is interesting to note that impurity addition (with some concentrations leads to a reduction of dielectric constant significantly and consequently leads to $l o w-\varepsilon_{\mathrm{r}}$ value dielectric material which is gaining more importance nowadays (as mentioned earlier). Higher concentrated glycine addition ( 0.8 and $1.0 \mathrm{~mol} \%$ ) leads to reduction of $\varepsilon_{\mathrm{r}}$ value $\left(\varepsilon_{\mathrm{r}}=2.359\right.$ and 3.514 respectively at $\left.35^{\circ} \mathrm{C}\right)$ significantly.

\section{Conclusions}

Epsomite single crystals added with glycine have been grown successfully by the free evaporation method and characterized by density, PXRD, SHG, microhardness, electrical (DC and AC), FTIR and UV-VisNIR spectral measurements. All the six crystals grown are found to be stable in normal atmosphere and transparent in the wavelength range 210-1100 nm.The PXRD analysis confirms the crystalline nature and indicates that doping does not lead to significant distortion in the crystal structure. Tuning the optical, mechanical and electrical properties of Epsomite crystals could be understood as possible bydoping with glycine. The crystals are found to be NLO active, mechanically soft and exhibit normal dielectric behavior. Analysis of the DC and AC electrical conductivity data indicates that the conductivity is due to the proton transport. The present study indicates that doping Epsomite with glycine leads to the discovery of promising NLO active and low- $\varepsilon_{\mathrm{r}}$ value dielectric materials. 


\section{References}

[1]. E.Ruiz - Agudo, C.V.Putnis and C.Rodriguez - Navarro (2008) Crystal Growth \& Des. 8, 2665

[2]. $\quad$ F.M.Rayan, W.Lehman, D.W.Feldman, J.Murphy (1974) J.Electrochem. Soc. - Solid State Sci. Technol.,p.1475

[3]. M.Ikeya, G.M.Hassan, H.Sasaoka, Y.Kinoshita, S.Takaki and C.Yamanaka (2000) Appl. Radiat. Isotopes 52, 1209

[4]. R.W.G.Wyckoff (1960) Crystal Structures ( $2^{\text {nd }}$ edn.) vol.3 (Interscience, New York) p.839

[5]. John A.Dean (Edn.) (1979) Lange's Handbook of Chemistry (12 ${ }^{\text {th }}$ edn.) (New York, McGraw Hill)

[6]. G.Sugaldino, G.Vaccari, D.Aquilano and M.Rubbo (1987) J.Cryst. Growth 83,523

[7]. $\quad$ S.Ramalingam, J.Podder and S.N.Kalkura (2001) Cryst. Res. Technol.36, 1357

[8]. I.A.Kasatkin (2002) Cryst. Res. Technol. 37, 193

[9]. S.Karan and S.P.Sen Gupta (2006) Indian J. Phys. 80, 781

[10]. C.K.Mahadevan (2008) Physica B, 403, 57

[11]. C.K.Mahadevan (2008) Physica B, 403, 3164

[12]. S.Ferdous and J.Podder (2009) J.Bangladesh Acad.Sci.33, 47

[13]. M.Rubbo, D.Aquilano and M.F.Angela (1985)J. Cryst. Growth 71, 470

[14]. S.A.Jibbouri, C.Strege and J.Ulrich (2002) J.Cryst. Growth 236, 400

[15]. K.Jayakumari and C.Mahadevan (1992) J.Optics 21, 22

[16]. K.Jayakumari, C.Mahadevan and D.Chandrasekharam (1993)J. Pure \& Appl. Phys. 5, 331

[17]. M.Theivanayagam and C.Mahadevan (2001)Bull. Mater. Sci. 24, 441

[18]. V.M.van Essen, H.A.Zondag, J.Cot Gores, L.P.J.Bleijiendaal, M.Bakker, R.Schuitema, W.G.J.vanHelden, Z.He and C.C.M. Rindt (2009) J. Solar Energy Engg. 131, 041014

[19]. S.Goma, C.M. Padma and C.K.Mahadevan (2006) Mater. Lett. 60, 3701

[20]. M.Meena and C.K.Mahadevan (2008) Cryst .Res. Technol. 43, 166.

[21]. T.H.Freeda and C.Mahadevan , Bull. Mater. Sci. 23, 335

[22]. M.Priya, C.M.Padma, T.H.Freeda, C.Mahadevan and C.Balasingh (2001) Bull. Mater. Sci. 24, 511.

[23]. H.Lipson and H.Steeple (1970) Interpretation of X-ray Powder Diffraction Patterns, [MacMillan,New York]

[24]. S.K.Kurtz and T.T.Perry (1968) J. Appl. Phys. 39, 3798.

[25]. J.M.Kavitha and C.K.Mahadevan (2013) Intl. J. Eng. Res. Appl. 3, 1931

[26]. N.NeelakandaPillai and C.K.Mahadevan (2007) Mater. Manuf. Processes, 22, 393.

[27]. C.M.Padma and C.K.Mahadevan (2008) Physica B 403, 1708

[28]. M.Priya and C.K.Mahadevan (2008) Physica B 403,67.

[29]. M.Meena and C.K.Mahadevan (2008) Mater. Lett. 62, 3742

[30]. S.Ramalingam, J.Podder and S.N.Kalkura (2003) J. Cryst. Growth 247, 523

[31]. G.Pasupathi and P.Philominathan (2008) Mater. Lett. 62, 4386

[32]. Y.L.Fur, R.Masse, M.Z.Cherkaoui and J.F.Nicoud (1975) Z.Kristallogr. 210, 856.

[33]. E.Meyer (1908) Z.Ver.Deut.Ing. 52, 645

[34]. S.Karan and S.P.Sen Gupta (2005) Mater.Sci. Engg. A398,198.

[35]. I.Bunget and M.Popseu (1984) Physics of Solid Dielectrics [Elsevier, New York].

[36]. P.Varotsos (1978) J. Phys. Lett. 39, L79. 